\title{
Methylene blue? Therapeutic Alternative in the Management of Septic Shock Refractory to Norepinephrine
}

\author{
Cristian Aragón-Benedí 1 , , Ana Pascual-Bellosta ${ }^{2}$, Sonia Ortega-Lucea ${ }^{2}$, \\ Luisa Lacosta-Torrijos ${ }^{2}$, Teresa Jiménez-Bernadó ${ }^{3}$, Javier Martínez-Ubieto ${ }^{2}$, Research \\ group in anesthesia, resuscitation and perioperative medicine of Institute for Health \\ Research Aragón
}

${ }^{1}$ Department of Anesthesia, Resuscitation and Pain Therapy,

Mostoles General University Hospital, Mostoles 28935, Madrid, Spain

${ }^{2}$ Department of Anesthesia,

Resuscitation and Pain Therapy, Miguel

Servet University Hospital, Zaragoza

50009, Spain

${ }^{3}$ Department of Health Sciences,

University of Zaragoza, Zaragoza 50009

Spain

\section{*Correspondence}

cristianaragon@outlook.com

(Cristian Aragón-Benedí)

\begin{abstract}
Introduction: Methylene blue is receiving special interest in perioperative and intensive care of patients with distributive shock due to its ability to block the action of nitric oxide and to antagonize deep vasodilation. Objective: The objective is to illustrate the use of the methylene blue, summarizing the perioperative management of a case with secondary vasoplegic syndrome due to a norepinephrine refractory septic shock and the response to methylene blue, reviewing the latest evidence of this therapeutic alternative. In practice:We describe the case of a 60 -year-old man, paraplegic, with septic shock due to a long evolution decubitus pressure ulcer. After two hours of surgery, the patient remained with hemodynamic deterioration despite high doses of vasopressin (3 IU/hour) and norepinephrine ( $2 \mu \mathrm{g} / \mathrm{kg} / \mathrm{min})$, therefore methylene blue was administered with two intravenous bolus doses of $50 \mathrm{mg}$ without adverse effects. After half an hour hemodynamic improvement was evidenced, allowing to decrease norepinephrine infusion and normalizing blood pressure. Finally, debridement of necrotic tissue, amputation and disarticulation of left coxofemoral joint was performed with subsequent transfer to the ICU and discharge to the spinal cord injury ward twenty eight days later. Conclusions: As it has been demonstrated in our patient, methylene blue is a therapeutic alternative to manage patients with persistent hypotension despite the use of various vasopressors during the management of vasoplegic syndrome secondary to septic shock.
\end{abstract}

\section{Keywords}

Septic shock, Methylene blue, Surgical intensive care, Vasoplegic syndrome

\section{Introduction}

Septic shock is characterized by systemic inflammation that evolves to a vasoplegic syndrome and it is associated with hypotension, low systemic vascular resistance (SVR) and increased requirements of fluids and vasopressors $[1,2]$. Thereby the organism is unable to achieve adequate perfusion of the target organs due to the lack of vascular tone and vasodilation. This vasodilation is produced by an autonomic dysregulation in the release of inflammatory mediators, such as L-arginine which ends up producing an increase in nitric oxide (NO) synthesis and cyclic guanosine monophosphate (cGMP) for final activation of soluble guanylate cyclase (sGC) in vascular smooth muscle [3-5].

Despite advances in vasopressor therapy, prolonged hypotension and poor tissue perfusion can lead to multiple organ failure (MOF) and achieving $20-50 \%$ of mortality in the cases of sepsis [1, 6].

Methylene blue has been used in perioperative and intensive care of patients with distributive shock, septic and anaphylactic, as well as cardiac surgery and liver transplantation [7-10]. This is due to its ability to antagonize the deep vasodilation by inhibiting certain cytokines of endothelial damage such as nitric oxide synthase (iNOS) and sGC, thereby producing blockage in both the synthesis and mode of action of NO.

The aim is to describe a case of a secondary vasoplegic syndrome due to norepinephrine refractory septic shock and the response to methylene blue, reviewing the latest evidence of this therapeutic alternative.

\section{In practice}

We present the clinical case of a 60 -year-old man (weight 98 $\mathrm{Kg}$ ), paraplegic due to a spinal cord injury 20 years ago, with unknown drug allergies and with a history of hypertension treatment with nebivolol, candesartan, mirtazapine and alfuzosin. The patient went to the emergency department for a long evolution decubitus pressure ulcer with a necrotic slough 
of about $40 \mathrm{~cm}$ in sacrum and trochanter (Fig. 1). After performing blood test, a leukocytosis $21,900 / \mu \mathrm{L}$, renal failure with creatinine 2.26 and $\mathrm{K}^{+} 6.3 \mathrm{mmol} / \mathrm{L}$ and procalcitonin $>$ $40 \mathrm{ng} / \mathrm{ml}$ were evidenced, all compatible with septic features.

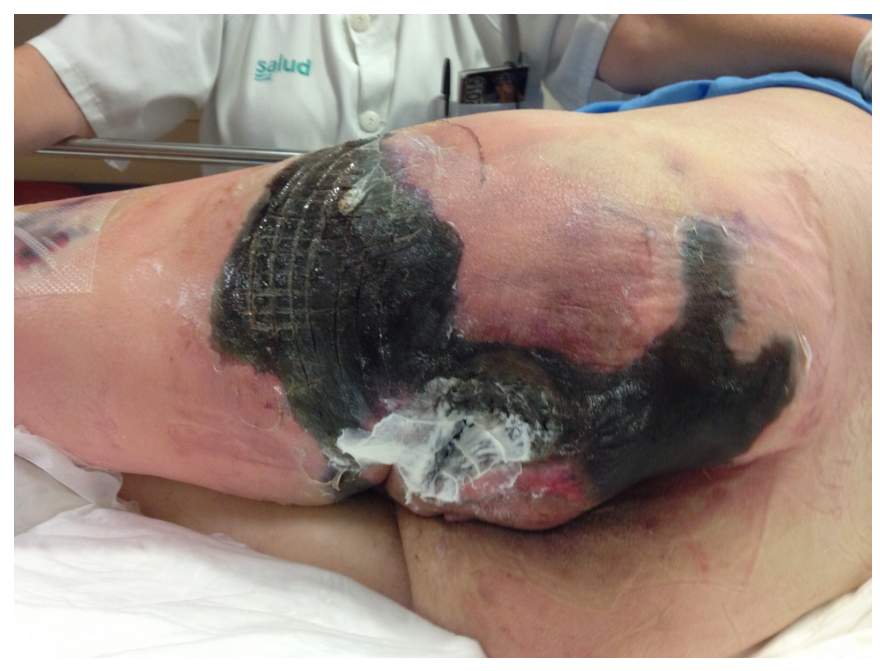

F I G URE 1. Decubitus Pressure Ulcer.

Thus treatment of intravenous antibiotic therapy with imipenem and vancomycin was started, and after an assessment done by the plastic surgery service an urgent surgical treatment was finally decided.

At the entrance to the operating room the blood pressure was $60 / 30 \mathrm{mmHg}$ so treatment was initiated with crystalloid and colloid to expand intravascular volume and $200 \mu \mathrm{g}$ phenylephrine and norepinephrine infusion of $0.5 \mu \mathrm{g} / \mathrm{kg} / \mathrm{min}$. Anesthesia was induced with midazolam $2 \mathrm{mg}$, fentanyl 250 $\mu \mathrm{g}$, propofol $150 \mathrm{mg}$ and rocuronium $80 \mathrm{mg}$ and it remained with sevoflurane $1-2 \%$, continuous infusion of rocuronium 25 $\mathrm{mg} / \mathrm{h}$, fentanyl $50 \mu \mathrm{g} / \mathrm{h}$ bolus and continuous infusion remifentanil $0.03-0.15 \mu \mathrm{g} / \mathrm{kg} / \mathrm{min}$. Central venous access at the right jugular was channeled, and invasive arterial blood pressure and continuos cardiac output monitoring through access of the left radial artery was performed. Mechanical ventilation was started with inspired fraction of $50 \%$, a volume $550 \mathrm{ml}$ with a rate of 15 to 17 breaths per minute and positive end-expiratory pressure (PEEP) of $7 \mathrm{~cm} \mathrm{H}_{2} \mathrm{O}$ maintaining arterial saturations above of $95 \%$.

At the beginning of the surgery the following hemodynamic parameters and arterial blood gases were observed: $\mathrm{pH} 7.12$, $\mathrm{pCO}_{2} 53 \mathrm{mmHg}, \mathrm{K}^{+} 6.2 \mathrm{mmol} / \mathrm{L}$, lactate $3.8 \mathrm{mmol} / \mathrm{L}$ and $\mathrm{Hb} 9.3 \mathrm{~g} / \mathrm{dL}$; blood pressure was maintained at $70 / 40 \mathrm{mmHg}$, heart rate at 110 beats $/ \mathrm{min}, \mathrm{EtCO}_{2}$ at $50 \mathrm{mmHg}, \mathrm{SpO}_{2}$ at $95 \%$ and central venous pressure (CVP) at $16 \mathrm{mmHg}$.

After two hours of evolution the patient remained with hemodynamic deterioration with blood pressure of 70/30 $\mathrm{mmHg}$ despite of administration of $3 \mathrm{IU} /$ hour of vasopressin infusion and giving a maximum dose of norepinephrine at $2 \mu \mathrm{g} / \mathrm{kg} / \mathrm{min}$, so it was decided to use methylene blue (Fig. 2). Methylene blue was administered with an interval of 20 minutes, two intravenous bolus doses of $50 \mathrm{mg}$ up to a total of $1 \mathrm{mg} / \mathrm{kg}$ without adverse effects of interest, except for a brief interference in the accuracy of the pulse oximetry and greenish staining urine (Fig. 3).
After half an hour of the methylene blue administration, hemodynamic improvement was evidenced and it was maintained over time for 3 hours allowing to decrease norepinephrine infusion to $1 \mu \mathrm{g} / \mathrm{kg} / \mathrm{min}$ and normalizing blood pressure at $100 / 70 \mathrm{mmHg}$.

During seven hours of surgery crystalloid $4500 \mathrm{ml}$ and colloid $1500 \mathrm{ml}$ were administered, with an approximate blood loss of $1700 \mathrm{ml}$. Total diuresis was maintained at $2450 \mathrm{ml}$ under furosemide administration of $10 \mathrm{mg}$ /hour. Furthermore it was necessary 7 red blood cell concentrates and 2 platelets pool maintaining at the end of the surgery a hematocrit of 17 $\%$ and haemoglobin of $5.3 \mathrm{~g} / \mathrm{dL}$.

Severe metabolic acidosis ( $\mathrm{pH}$ 7.12) and hyperkalemia $\left(\mathrm{K}^{+}\right.$ $6.2 \mathrm{mmol} / \mathrm{L})$ were managed with bicarbonate total dose of $500 \mathrm{ml}$ (1 molar) and a $4 \mathrm{~g}$ of calcium gluconate. Control coagulopathy was achieved (international normalized ratio 1.5, prothrombin activity $42 \%$, fibrinogen derivative $10 \mathrm{~g} / \mathrm{L}$ ) using $20 \mathrm{mg}$ of vitamin $\mathrm{K}$, tranexamic acid $1.5 \mathrm{~g}$ and a unit of fresh frozen plasma (FFP).

During the surgery, the debridement of the necrotic tissue that spread from the skin to internal compartments of the gluteus, thigh and left leg with involvement of the coxofemoral joint, rectal wall, and external anal sphincter was performed (Fig. 4).

Finally, with the collaboration of Traumatology Service an amputation and disarticulation of left coxofemoral joint and musculocutaneous reconstruction using the anterior compartment of thigh was carried out.

After completing the surgery the patient was transferred to the ICU and in the first post-surgery hours the patient maintained a severe septic shock with MOF and severe metabolic acidosis so that a continuous venovenous hemodiafiltration was started. Twenty-eight days later the patient was discharged from the ICU to the spinal cord injury ward managed by the Plastic Surgery Service.

\section{Discussion}

One of the causes of the resistance to the use of norepinephrine and vasopressin in our patient may be the chronic treatment with alfuzosin and nebivolol. Alfuzosin is a drug used for benign prostatic hyperplasia that blocks the effect of $\alpha 1$ adrenergic receptors, lowering blood pressure by postsynaptic blockade, inhibiting the vasoconstrictive effect of norepinephrine [12]. On the other hand, nebivolol is a selective third-generation beta-blocker against beta-1 receptors with vasodilation effects mediated by the release of NO [13].

Although methylene blue is not new, since Schneider et al. [14] first described it in sepsis shock patients, the data of its usage are limited [15]. Most of the observational studies and only two existing clinical trials in the literature to date (Kirov et al., including 20 patients [16] and Memis et al., including 30 patients [17]) evidence a significant increase in mean arterial pressure (MAP), pulmonary artery pressure, and SVR after use.

Other observational studies as Andresen et al [18] further showed a decrease in serum lactate at 24 hours due to selective increase of mesenteric flow. Juffermans et al. [19] con- 
- $\operatorname{MAP}(\mathrm{mmHg}) \diamond \mathrm{HR}$ (beats $/ \mathrm{min}) \quad \square \operatorname{CVP}(\mathrm{mmHg})$

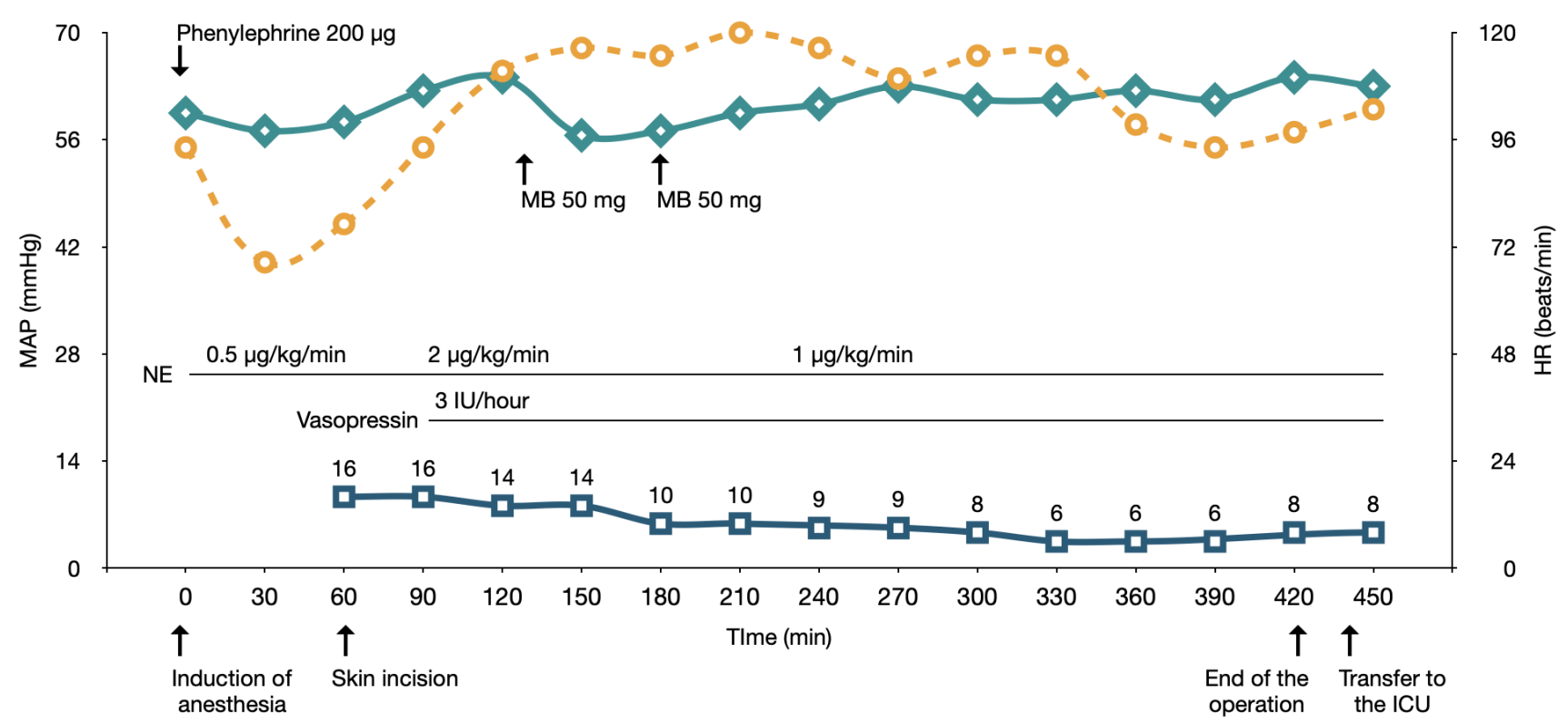

F I G U R E 2. Use of Vasoactive Drugs and Hemodynamic Parameters During Anesthesia in the Operating Room. Phenylephrine, $\alpha 1$ adrenergic agonist; NE, norepinephrine $\alpha 1 \alpha 2$ and $\beta 1$ adrenergic agonist; vasopressin, V1 vasopressor and $V 2$ antidiuretic effect; $M B$, methylene blue inhibits nitric oxide synthase (iNOS) and soluble guanylate cyclase (sGC).

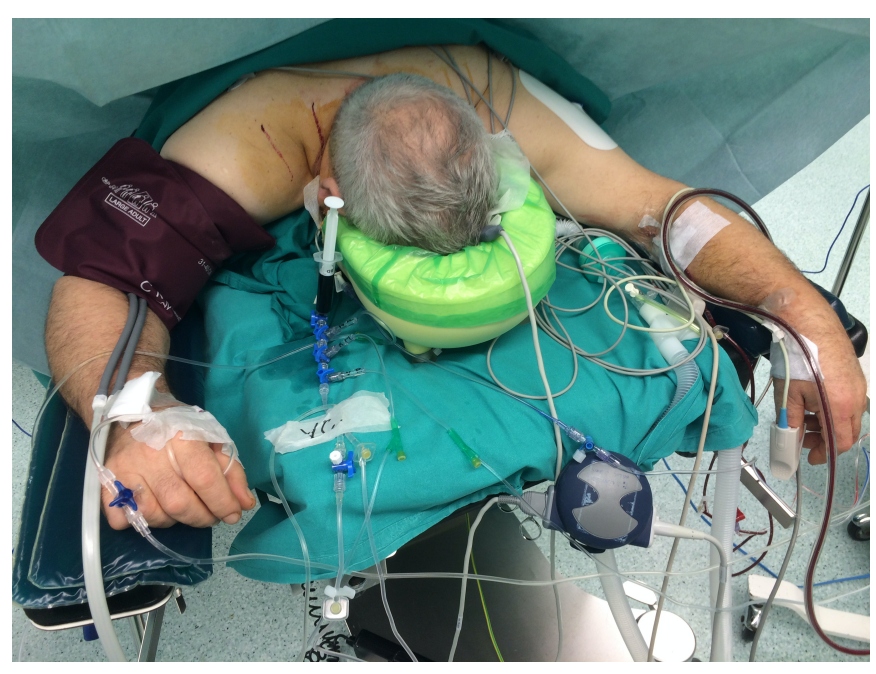

F I G U R E 3. Central Methylene Blue Bolus.

cluded that methylene blue causes a transient effect and dosedependent increasing cardiac output, MAP and SVR, although like Zhang et al. [20] demonstrated that high doses of methylene blue ( 5 to $20 \mathrm{mg} / \mathrm{kg}$ ) worsened myocardial depression, and from $7 \mathrm{mg} / \mathrm{kg}$ may even compromise splanchnic perfusion [19].

If methylene blue is compared during sepsis with other NO inhibitors, vasopressin decreases cardiac output while methylene blue does not change or even increases cardiac output $[1,11,21]$.

Although the delayed onset of the hemodynamic response of methylene blue is transient and does not modify the natural history of septic shock, it allows a dose reduction of vasopres-

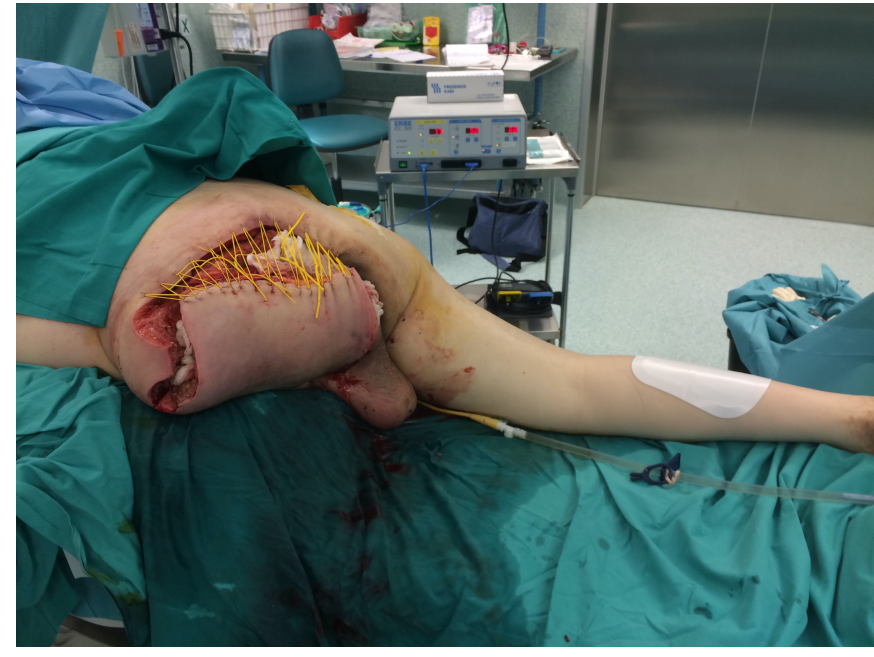

F I GURE 4. Amputation and Disarticulation of Left Coxofemoral Joint and Musculocutaneous Reconstruction.

sors, inotropic support, fluid therapy and blood transfusions thereby reducing renal, respiratory complications and accelerating postoperative recovery, having described a reduction in mortality of up to $21.4 \%$ in patients with vasoplegic syndrome $[1,22-24]$.

The dosing schedule is a single intravenous dose of methylene blue 1 to $2 \mathrm{mg} / \mathrm{kg}$, and a second dose can be repeated after 20 minutes and a continuous infusion at $2 \mathrm{mg} / \mathrm{kg}$ within 6 hours in patients who persists the hypotension after at least an infusion of $0.5 \mu \mathrm{g} / \mathrm{kg} / \mathrm{min}$ of norepinephrine [1, 3, 23]. 


\section{Conclusions}

It is relevant to mention that it should be early administered and not be administered only as a rescue measure since its effect and usefulness diminish significantly once MOF is has been established [1, 22].

Although more randomized studies are needed to identify its exact role in septic shock, as it has been demonstrated in our patient, methylene blue is already considered as a rescue, adjuvant and second-line therapeutic alternative to manage patients with persistent hypotension despite the use of various vasopressors during the perioperative management of the vasoplegic syndrome secondary to septic shock while etiological treatment is performed.

\section{ACKNOWLEDGEMENTS}

Other contributing authors from the Research Group in Anesthesia, Resuscitation, and Perioperative Medicine of Institute for Health Research Aragón (IIS Aragón) for this study are: Jesús Gil-Bona, Fernando Martínez-Ubieto, Luis Alfonso Muñoz-Rodríguez, Guillermo Pérez-Navarro, Berta Pérez-Otal, Natividad Quesada-Gimeno, Lucía TardósAscaso, Sara Visiedo-Sanchez.

\section{CONFLICTS OF INTEREST}

There is no conflict of interest on the part of any author.

\section{AUTOR CONTRIBUTION}

Each author has participated sufficiently in the work to take public responsibility for appropriate portions of the content.

\section{INFORMED CONSENT STATEMENT}

Informed written consent was obtained from the patient for publication of this report and any accompanying images.

\section{ETHICAL APPROVAL}

The study was approved by the Clinical Research Ethics Committee of the Miguel Servet University Hospital in Zaragoza.

\section{SUPPORTIVE FOUNDATIONS}

Supported by ERDF (FEDER) Operational Programme of Institute for Health Research Aragón (IIS Aragón) No. B26_17D.

\section{REFERENCES}

[1] Hosseinian L, Weiner M, Levin MA, et al. Methylene Blue: Magic Bullet for Vasoplegia?. Anesth Analg. 2016;122:194-201.

[2] Shanmugam G. Vasoplegic syndrome-the role of methylene blue. Eur J Cardiothorac Surg. 2005;28:705-710.
[3] Carrillo-Esper R, Sosa-García JO, Carrillo-Córdova JR, et al. Azul de metileno para el manejo del choque séptico refractario a vasopresores. Rev Mex Anest. 2010;33:214-219.

[4] Manghelli J, Brown L, Tadros HB,et al. A reminder of methylene blue's effectiveness in treating vasoplegic syndrome after on-pump cardiac surgery. Tex Heart Inst J. 2015;42:491-494.

[5] Evora PR. Methylene Blue Is a Guanylate Cyclase Inhibitor That Does Not Interfere with Nitric Oxide Synthesis. Tex Heart Inst J. 2016;43:103.

[6] Huet O, Chin-Dustin J. Septic shock: desperately seeking treatment. Clin Sci. 2014;126:31-39.

[7] Bauer CS, Vadas P, Kelly KJ. Methylene blue for the treatment of refractory anaphylaxis without hypotension. Am J Emerg Med. 2013;31:264.e3-5.

[8] Lo JC, Darracq MA, Clark RF. A review of methylene blue treatment for cardiovascular collapse. J Emerg Med. 2014;46:670-79.

[9] Evora PR. Methylene Blue and Cardiovascular Collapse. J Emerg Med. 2016;50:126-127.

[10] Pasin L, Umbrello M, Greco T, et al. Methylene blue as a vasopressor: a meta-analysis of randomised trials. Crit Care Resusc. 2013;15:42-48.

[11] Stocche RM, Garcia LV, Reis MP, et al. Methylene blue to treat anaphylaxis during anesthesia: case report. Rev Bras Anestesiol. 2004;54:809-814.

[12] Mercanoglu G, Semen O. Nitric oxide mediated the effects of nebivolol in cardiorenal syndrome. Iran J Basic Med Sci. 2019;22:1314-1324.

[13] In Duk O, Eunsil S, Jong-Mi J, et al. Use of methylene blue in vasoplegic syndrome that developed during non-cardiac surgery: A case report. Anesth Pain Med. 2019;14:460-464.

[14] Schneider F, Lutun P, Hasselmann M, et al. Methylene blue increases systemic vascular resistance in human septic shock. Preliminary observations. Intensive Care Med. 1992;18:309-311.

[15] Paciullo CA, Mcmahon horner D, Hatton KW, et al. Methylene blue for the treatment of septic shock. Pharmacotherapy. 2010;30:702-715.

[16] Kirov MY, Evgenov OV, Evgenov NV, et al. Infusion of methylene blue in human septic shock: a pilot, randomized, controlled study. Crit Care Med .2001;29:1860-1867.

[17] Memis D, Karamanlioglu B, Yuksel M, et al. The influence of methylene blue infusion on cytokine levels during severe sepsis. Anaesth Intensive Care. 2002;30:755-762.

[18] Andresen M, Dougnac A, Díaz O, et al. Use of methylene blue in patients with refractory septic shock: impact on hemodynamics and gas exchange. J Crit Care. 1998;13:164-168.

[19] Juffermans NP, Vervloet MG, Daemen-Gubbels CR, et al. A dose finding study of methylene blue to inhibit nitric oxide actions in the hemodynamics of human septic shock. Nitric Oxide. 2010;22:275-280.

[20] Zhang H, Rogiers P, Preiser JC, et al. Effects of methylene blue on oxygen availability and regional blood flow during endotoxic shock. Crit Care Med. 1995;25:1711-1721.

[21] Lavigne D. Vasopressin and methylene blue: alternate therapies in vasodilatory shock. Semin Cardiothorac Vasc Anesth. 2010;14:186-189.

[22] Carrillo-Esper R, Nuñez-Monroy FN, Alvarado-Martinez C. Azul de metileno en choque séptico refractario. Rev Asoc Mex Med Crit Ter Int. 1999;13:28-35.

[23] Mccartney SL, Duce L, Ghadimi K. Intraoperative vasoplegia: methylene blue to the rescue!. Curr Opin Anaesthesiol. 2018;31:43-49.

[24] Booth AT, Melmer PD, Tribble B, et al. Methylene Blue for Vasoplegic Syndrome. Heart Surg Forum. 2017;20:E234-E238.

How to cite this article: Cristian Aragón-Benedí, Ana PascualBellosta, Sonia Ortega-Lucea, Luisa Lacosta-Torrijos, Teresa Jiménez-Bernadó, Javier Martínez-Ubieto, et al. Methylene blue? Therapeutic Alternative in the Management of Septic Shock Refractory to Norepinephrine. Signa Vitae. 2020;16(2):199-202. doi:10.22514/sv.2020.16.0063. 